Check for updates

Cite this: RSC Adv., 2017, 7, 49568

Received 25th September 2017

Accepted 19th October 2017

DOI: 10.1039/c7ra10585a

rsc.li/rsc-advances

\section{Fabrication of free-standing membranes with tunable pore structures based on the combination of electrospinning and self-assembly of block copolymers $\uparrow$}

\begin{abstract}
Meimei Zhou, (DD *a Yi-nan Wu, ${ }^{b}$ Pingping Luo, ${ }^{a}$ Jiqiang Lyu, ${ }^{a}$ Dengrui $M u,{ }^{a}$ Aowen $\mathrm{Li}{ }^{a}$ Fengting $\mathrm{Li}^{\mathrm{b}}$ and Guangtao Li (D) *c

In this study, free-standing composite membranes with tunable pore structures are fabricated by combining electrospinning and block copolymer (BCP) self-assembly and a facile biomimetic surface modification method is employed for improvement of the interfacial interaction in the composite membranes. Firstly, polystyrene-block-poly(2-vinyl pyridine) (PS-b-P2VP) solution is drop-coated onto a electrospun PVA/ $\mathrm{SiO}_{2}$ fiber mat which provides mechanical reinforcement, fabricating symmetric (thickness, $17 \pm 2 \mu \mathrm{m}$ ) and asymmetric (thickness, $\sim 5 \mu \mathrm{m}$ ) composite membranes. The pore structures in the PS- $b$-P2VP matrix are realized by selectively swelling the P2VP block in hot ethanol and can be tuned by adjusting swelling time and swelling temperature. Moreover, pretreating the electrospun $\mathrm{PVA} / \mathrm{SiO}_{2}$ fibres with adhesive polydopamine (PDA) coating improves the adherence between the BCP layer and the electrospun fibres remarkably. The results of ultrafiltration performance test show the excellent performance of the composite membrane for the immobilization and capture nanoparticles (NPs).
\end{abstract}

\section{Introduction}

Nonwoven fibrous membranes fabricated by electrospinning are promising candidates for filtration and separation because of their outstanding properties, such as excellent tensile strength, large surface area per unit volume, high porosity, interconnected porous structure, and design versatility. ${ }^{\mathbf{1 - 3}}$ However, their drawbacks, which are attributed to the geometrical structure of their pores, wide pore size distribution, and undesirable macrovoid formation across the entire membrane thickness, result in decreased retention and poor selectivity. ${ }^{4} \mathrm{As}$ a result, the practical applications of electrospun fibrous membranes are limited.

Recently, porous membranes based on block copolymers (BCPs) have attracted considerable attention due to their tunable nanoporous structures, which are achieved via microphase separation. ${ }^{5-7}$ Several studies have indicated that porous BCP membranes show great potential in ultrafiltration. ${ }^{\mathbf{8} 9}$ For

${ }^{a}$ Key Laboratory of Subsurface Hydrology and Ecological Effects in Arid Region, Ministry of Education, School of Environmental Science and Engineering, Chang'an University, 710054 Xi'an, China.E-mail:mmzhou@chd.edu.cn

${ }^{b}$ College of Environmental Science \& Engineering, Tongji University, 1239, Siping Road, Shanghai, 200092, China. E-mail: Fengting@tongji.edu.cn

'Department of Chemistry, Key Lab of Organic Optoelectronics \& Molecular Engineering, Tsinghua University, Beijing 100084, China

$\dagger$ Electronic supplementary information (ESI) available. See DOI: $10.1039 / \mathrm{c} 7 \mathrm{ra} 10585 \mathrm{a}$ example, Uehara et al. demonstrated that a series of flexible nanoporous membranes from PS- $b$-PMMA exhibiting a bicontinuous crystalline-amorphous phase-separation system have potential application in size-selective molecular diffusion at the nanoscale. ${ }^{\mathbf{1 0}}$ However, low mechanical strength of free-standing BCP membranes is an obstruction for their ultrafiltration application. In order to enhance the mechanical properties, non-solvent induced phase separation (NIPS) process has been developed to produce integral asymmetric block copolymer membranes with ordered cylindrical nanopores on top of the disordered layer. ${ }^{11,12}$ By using this method, Xie et al. prepared membranes from polysulfone-based block copolymers which show greatly improved mechanical strength. ${ }^{13}$ Schacher et al. also obtained self-supporting porous membranes with double stimuli-responsiveness from a polystyrene-block-poly $(N, N$ dimethylaminoethyl methacrylate) (PS- $b$-PDMAEMA) block copolymer. ${ }^{14}$ However, the membranes resulting from NIPS will be expensive due to the increase of BCPs use. Therefore, fabricating nanoporous BCP membranes supported on micro/macroporous substrates, such as the commercial polysulfone, ${ }^{15}$ polyethersulfone, ${ }^{16-18}$ polyacrylonitrile, ${ }^{19}$ polyvinylidene fluoride ${ }^{20}$ microfiltration membrane, has been gaining as an alternative. In this study, a nanoporous BCP membrane was combined with an electrospun macroporous membrane to obtain a composite membrane with enhanced mechanical stability and improved the nanoparticle (NP) entrapment efficiency of the latter. 
However, weak adhesion and even peeling at the interface results from the incompatible surface properties of the nanoporous BCP layer and the substrate. These issues further hinder the extensive application of BCPs to perfect ultrafiltration. Various surface modification techniques have been proposed to improve the interfacial interaction between the different phases of a composite membrane..$^{21-25}$ However, the proposed methods themselves exhibit drawbacks, such as the use of complex instruments, limitations in substrate size and shape, and elaborate procedures, which restrict their widespread implementation. Messersmith et al. offered a solution to this problem by proposing a facile and versatile surface modification method of coating surfaces with an adhesive polydopamine (PDA) film. ${ }^{26}$ The oxidant-induced auto-polymerization of dopamine to nearly any surface allows for the direct dipping of a substrate into an aqueous dopamine solution with a slightly basic $\mathrm{pH}$ to realize PDA coating. The ultrathin and highly hydrophilic coating exhibits a powerful adhesive ability to attach foreign objects, indicative of a favorable property for improving the interface performance of composite membrane and enhancing the adhesion between two incompatible phases. ${ }^{27-29}$ Compared with other surface modification methods, PDA coating is attractive because of its versatility, simplicity, low cost, and nonpolluting property.

Therefore, in this work, adhesive PDA coating was used to improve the interfacial interaction between the electrospun fibers and BCP layer in the composite membranes which are fabricated by drop-coating polystyrene-block-poly(2-vinyl pyridine) (PS- $b$-P2VP) onto the electrospun $\mathrm{PVA} / \mathrm{SiO}_{2}$ macroporous membranes (Fig. 1). The nanopores in the PS- $b$-P2VP matrix were produced by the selective swelling of P2VP in hot ethanol. Both pore structure and pore size were adjusted by regulating swelling temperature and swelling time. The

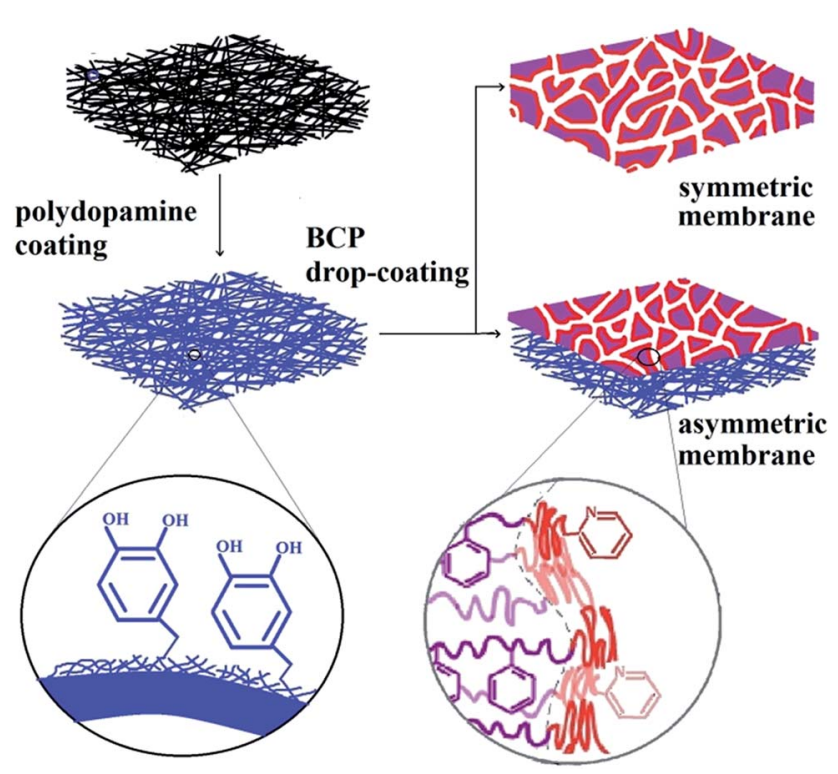

Fig. 1 Schematic illustration of free-standing composite membranes by combining electrospinning with phase-separation of block copolymer. obtained hierarchical composite membranes exhibited excellent rejection rate for Au NPs with an average diameter of $\sim 50 \mathrm{~nm}$, suggesting the considerable potential in separation.

\section{Experimental}

\section{Materials and methods}

Polyvinyl alcohol (PVA) was purchased from Alfa Aesar. Tetraethyl orthosilicate (TEOS) were obtained from Sinopharm Chemical Reagent Beijing Co., Ltd. Dopamine hydrochloride and trismetylaminomethane were obtained from J\&K Scientific Ltd. Tetrahydrofuran (THF), phosphoric acid $\left(\mathrm{H}_{3} \mathrm{PO}_{4}\right)$ and hydrochloric acid $(\mathrm{HCl})$ were purchased from Beijing Chemical Reagents Company and used without any purification. Polystyrene-block-poly(2-vinyl pyridine) (PS-b-P2VP) prepared via reversible addition fragmentation chain transfer (RAFT) polymerization described in the ESI. $\dagger$

\section{Electrospinning of $\mathrm{PVA} / \mathrm{SiO}_{2}$ fibrous membrane}

TEOS (4.16 g) and deionized water (3.96 g) were mixed in a small beaker and then aqueous $\mathrm{H}_{3} \mathrm{PO}_{4}$ was added by dropwise under vigorous stirring. The molar ratio of the composition was TEOS : $\mathrm{H}_{2} \mathrm{O}: \mathrm{H}_{3} \mathrm{PO}_{4}=1: 11: 0.1$. After stirring for $60 \mathrm{~min}$, $10 \mathrm{wt} \%$ PVA $(8.0 \mathrm{~g})$ was gradually dropped into the resulting silica gels, then the mixture was reacted in $60{ }^{\circ} \mathrm{C}$ oil bath by magnetically stirring for 2 hours. The obtained homogeneous solution was put into a $10 \mathrm{~mL}$ plastic syringe with a stainless steel needle. The needle was connected to a high-voltage generator as anode while the cathode was connected to a collector covered with a piece of aluminum foil. A voltage of $16 \mathrm{kV}$ and a constant flow rate of $16 \mu \mathrm{m} \mathrm{min}{ }^{-1}$ were applied to the solution with the tip-to-collector distance was $20 \mathrm{~cm}$. After electrospinning for 5 hours, the collected $\mathrm{PVA} / \mathrm{SiO}_{2}$ fibers with certain thickness were peeled off the surface of aluminum foil and dried at $80{ }^{\circ} \mathrm{C}$ under vacuum for 12 hours to enhance crosslinking of PVA and silica. Then the $\mathrm{PVA} / \mathrm{SiO}_{2}$ fibrous membranes were cut into circular shapes about $25 \mathrm{~mm}$ of diameter for next experimental usage.

\section{Modification of $\mathrm{PVA} / \mathrm{SiO}_{2}$ fibrous membrane}

The PVA/SiO ${ }_{2}$ fibers were modified with PDA by immersing the membrane into $2 \mathrm{mg} \mathrm{mL} \mathrm{mL}^{-1}$ dopamine hydrochloride solution which was prepared by dissolution of dopamine hydrochloride in Tris-HCl buffer aqueous solution (10 mM, pH 8.5)..$^{28,30}$ After coating 12 hours, the $\mathrm{PVA} / \mathrm{SiO}_{2}$ fibrous membranes were rinsed with deionized water and blow-dried with nitrogen.

\section{Preparation of symmetric composite membrane}

PS- $b$-P2VP synthesized in our work was dissolved in THF to yield homogeneous solutions with different concentrations. Then $1.0 \mathrm{~mL}$ of the solution was slowly dropped on the $\mathrm{PVA} / \mathrm{SiO}_{2}$ fibrous membranes or PDA-modified $\mathrm{PVA} / \mathrm{SiO}_{2}$ fibrous membranes. The PS- $b$-P2VP solution was absorbed by the macropores in the fibrous membranes to form composite structures. Next, confined swelling-induced pore-making strategy was used to generate nanopores in the composite 
membranes. The composite membranes were dipped in ethanol bath for a given time at different temperature, and then placed at room temperature for 6 hours after redrawing from ethanol bath for volatilization of ethanol.

\section{Preparation of asymmetric composite membrane}

PDA-modified PVA/ $\mathrm{SiO}_{2}$ fibrous membranes were put into water for $60 \mathrm{~min}$. Then the membranes saturated with water were placed at room temperature for a period time to volatilize the water on the surface. 1-3 wt $\%$ PS- $b-\mathrm{P} 2 \mathrm{VP} / \mathrm{THF}$ solution was dropped on the membranes lightly. Instantly the membranes were inclined $45^{\circ}$ left and right to ensure the uniform spread of PS- $b$-P2VP solution. Then the pore-making strategy which was same as that of symmetric composite membranes was taken.

\section{Ultrafiltration performance}

Golden particles prepared in the laboratory with diameter of $\sim 50 \mathrm{~nm}$ were dispersed in water to get a red dispersion and suspension. Then symmetric composite membrane with a thickness of $17 \pm 2 \mu \mathrm{m}$ and average nanopores of $38 \mathrm{~nm}$ was used to filter the golden particles in room temperature.

\section{Characterization}

The morphologies of the fabricated membranes were observed using a field emission scanning electron microscopy (FESEM) on a JEOL JSM-5400 system. The surface chemical structures of the $\mathrm{PVA} / \mathrm{SiO}_{2}$ electrospun fibers before and after PDA coating were characterized by Attenuated Total Reflection-Fourier Transform Infrared Spectra (ATR-FTIR) on a Perkin Elmer Spectrum GX at range of $4000-400 \mathrm{~cm}^{-1} \cdot \mathrm{N}_{2}$ adsorptiondesorption was measured on a Micrometrics ASAP-2020 sorption meter at $77 \mathrm{~K}$. Before analysis, the samples were degassed at $323 \mathrm{~K}$ under a vacuum for $360 \mathrm{~min}$. Brunauer-Emmett-Teller (BET) method was employed to calculate the specific surface area in the range of relative pressure from 0.05 to 0.2 and Barrett-Joyner-Halenda (BJH) model was used to calculate the pore volume and pore size distributions of the symmetric composite nanoporous membrane. Transmission electron microscope (TEM) imaging was collected on an H-7650B electron microscope operating at $120 \mathrm{kV}$ by dispersing the fibers in ethanol and then drop-coating the copper grids. The wetting ability of the $\mathrm{PVA} / \mathrm{SiO}_{2}$ fibrous membrane before and after PDA coating was conducted with a video-based OCA 15 contact angle goniometer at $20{ }^{\circ} \mathrm{C}$.

\section{Results and discussion}

\section{Electrospun $\mathrm{PVA} / \mathrm{SiO}_{2}$ fibrous membrane}

In the current work, a $\mathrm{PVA} / \mathrm{SiO}_{2}$ fibrous membrane prepared by electrospinning following methods described in previous report ${ }^{31}$ was selected as the macroporous skeleton of the composite membrane. Aside from sufficient mechanical strength, which is necessary for membrane filters, solvent resistance is required for an electrospun fibrous support given that the BCP coating dissolves in organic solvent. The enhanced stability in water or organic solvents and the improved mechanical properties of the
$\mathrm{PVA} / \mathrm{SiO}_{2}$ fibers can be achieved by modulating the ratio of TEOS and PVA because of the crosslinking of PVA chains with the silica network via $\mathrm{Si}-\mathrm{O}-\mathrm{C}-\mathrm{O}-\mathrm{Si}$ bridges. ${ }^{32,33}$ For the preparation of the $\mathrm{PVA} / \mathrm{SiO}_{2}$ fibrous membrane, the collection distance, the solvents and some other parameters have effects on the morphology and diameter of the obtained fibers. In general, increasing the collection distance will reduce the electric field intensity but facilitate the volatilization of solvents, which ultimately have a combined effect on the diameter of fibers. The surface tension of the precursor solution and the volatility of the solvent also play an important role in the morphology of the fibers. For example, higher surface tension may result in fibers with bead defects. One of the most common solvents for electrospinning is water, which is also the benign solvent for the PVA. Thus, in our work, the spinning solution was prepared by dissolve the precursor in $\mathrm{H}_{2} \mathrm{O}$ and the collection distance of $15 \mathrm{~cm}$ was applied. The SEM images and optical photo of the $\mathrm{PVA} / \mathrm{SiO}_{2}$ fibrous membrane are presented in Fig. 2. Smooth-surfaced fibers with regular morphologies and diameters of approximately $1000 \mathrm{~nm}$ are randomly distributed in the membrane. A three-dimensional framework with a pore size ranging from several microns to tens of microns was formed. The TEM image of the original electrospun fibers is shown in Fig. 2d, which confirms that the fibers are homogeneous and have no extra shells. The fibrous membrane was briefly heated to $80^{\circ} \mathrm{C}$ to further crosslink PVA and TEOS to improve the mechanical strength and solvent resistance of the membrane.

\section{Modification of $\mathrm{PVA} / \mathrm{SiO}_{2}$ fibrous membrane}

After coating with PDA, the morphology and integrity of the membrane and fibers were retained (Fig. 3a). However, it can be
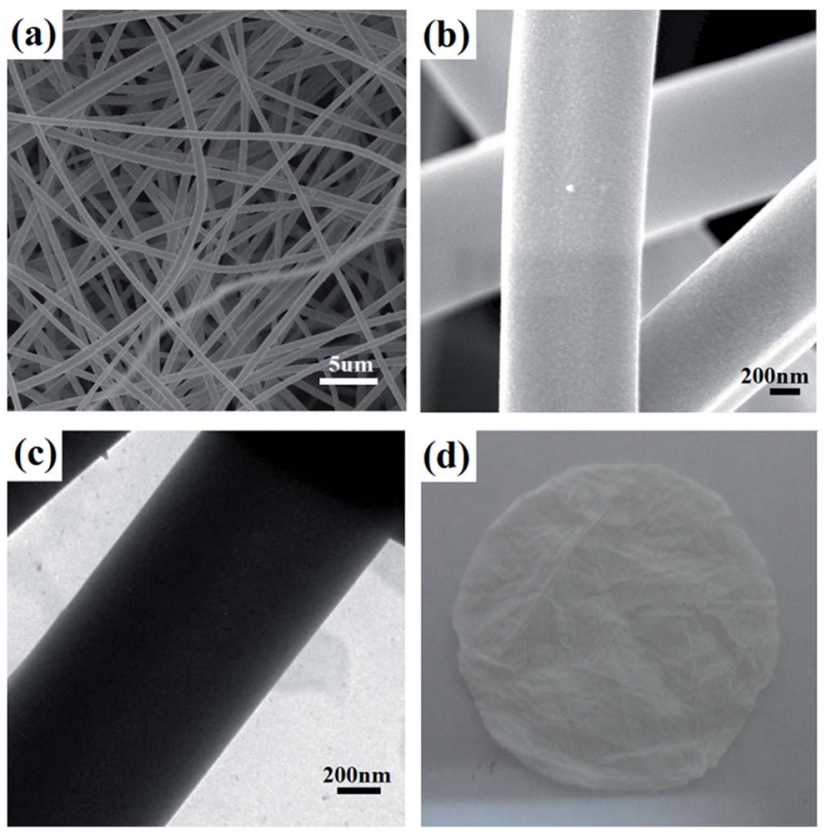

Fig. 2 ( $a$ and b) SEM images of the as-prepared $\mathrm{PVA} / \mathrm{SiO}_{2}$ fibrous membrane at different level of magnification; (c) TEM image of the asprepared $\mathrm{PVA} / \mathrm{SiO}_{2}$ fibers; (d) optical photo of the as-prepared $\mathrm{PVA} / \mathrm{SiO}_{2}$ fibrous membrane. 
seen from the SEM image at higher magnification that the surface of the fibers are rough after PDA coating (Fig. 3b), which results from the formation of a thin layer with densely dispersed PDA dots. The thickness of the PDA layer is approximately $30 \mathrm{~nm}$, as shown in the TEM image in Fig. 3c. The color of the PVA/SiO membrane changed from white to dark brown (Fig. 3d), also providing evidence of the formation of the PDA layer. ${ }^{26,34}$

The ATR-FTIR spectra of the as-prepared $\mathrm{PVA} / \mathrm{SiO}_{2}$ fibrous membrane and PDA-coated $\mathrm{PVA} / \mathrm{SiO}_{2}$ fibrous membrane were recorded to determine the surface chemical composition, and the results are shown in Fig. 4a. The characteristic peaks at $1445-1610 \mathrm{~cm}^{-1}$ of the ATR-FTIR spectrum of the PDA-coated $\mathrm{PVA} / \mathrm{SiO}_{2}$ fibrous membrane are assigned to the $\mathrm{C}-\mathrm{C}$ vibration of benzene ring moiety and the $\mathrm{N}-\mathrm{H}$ bending vibration of the dopamine molecules, directly proving the formation of PDA on the surfaces of the fibers.

Static water contact angle measurements were conducted to study the surface wettability of the as-prepared $\mathrm{PVA} / \mathrm{SiO}_{2}$ fibrous membrane before and after PDA coating. As shown in Fig. 4b, after coated with a layer of PDA, the water contact angle of PVA/ $\mathrm{SiO}_{2}$ fibrous membrane decreased from $132^{\circ}$ to $119^{\circ}$ owing to the hydrophilic groups such as imino and benzene hydroxyl groups in the PDA chains.

\section{Preparation of symmetric composite membrane}

Firstly, the as-prepared electrospun $\mathrm{PVA} / \mathrm{SiO}_{2}$ fibrous membrane without prior surface modification was used to prepare the free-standing composite membrane by drop coating a $2 \mathrm{wt} \%$ solution of PS- $b$-P2VP (Mn (PS) $=62,400 \mathrm{~mol} \mathrm{~kg}^{-1}$; Mn $\left.(\mathrm{P} 2 \mathrm{VP})=24,150 \mathrm{~mol} \mathrm{~kg}^{-1}\right)$ in THF. The macropores in the
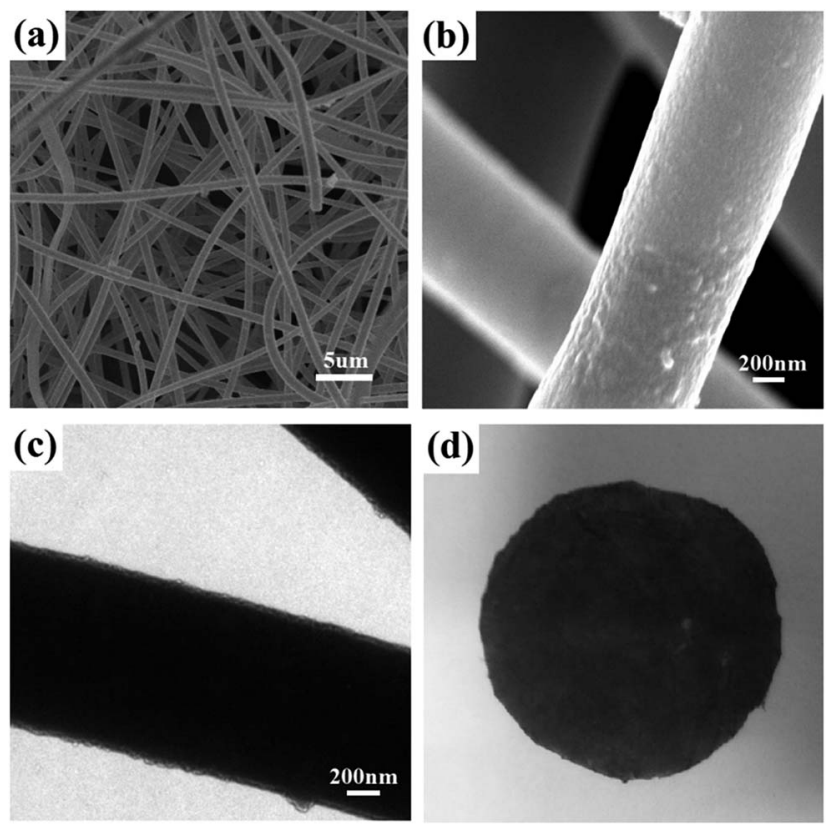

Fig. 3 (a and b) SEM images of the PDA-coated $\mathrm{PVA} / \mathrm{SiO}_{2}$ fibrous membrane at different magnification levels; (c) TEM image of the PDAcoated fibers; (d) optical photo of the PDA-coated $\mathrm{PVA} / \mathrm{SiO}_{2}$ fibrous membrane.
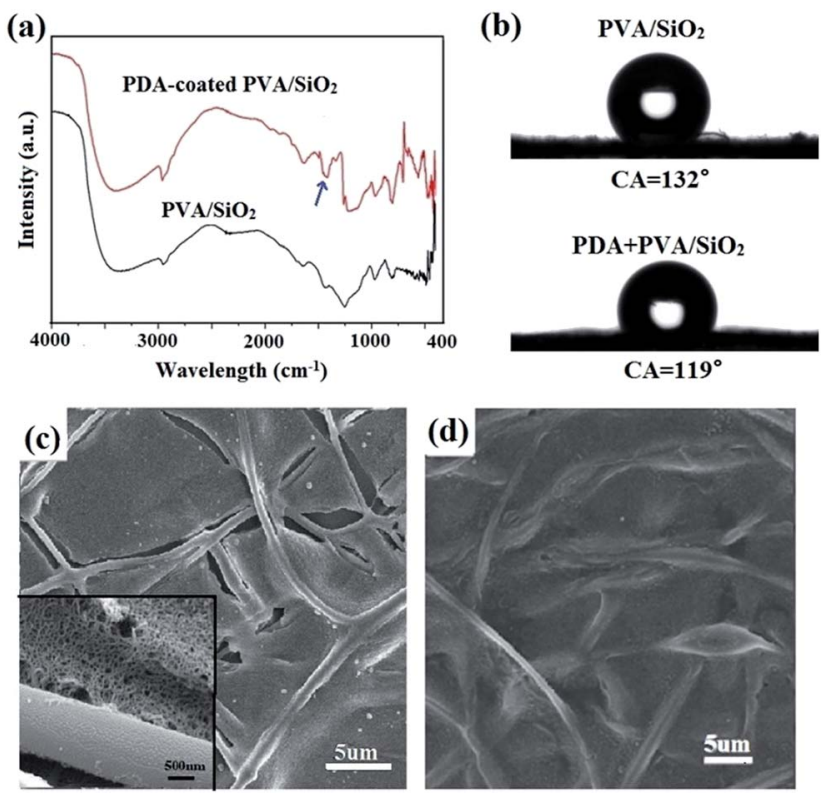

Fig. 4 (a) ATR-FTIR spectra and (b) static contact angle images of asprepared $\mathrm{PVA} / \mathrm{SiO}_{2}$ fibrous membrane before and after PDA coating; SEM images of (c) PS- $b$-P2VP/electrospun $\mathrm{PVA} / \mathrm{SiO}_{2}$ fibers composite membrane (inset is the SEM image at higher magnification level) and (d) PS- $b$-P2VP/PDA-coated electrospun $\mathrm{PVA} / \mathrm{SiO}_{2}$ fibers composite membrane after swelling in $70^{\circ} \mathrm{C}$ ethanol for 6 hours.

fibrous membrane were filled by the PS- $b$-P2VP filler (Fig. S1a $\dagger$ ). The skeleton of the fibrous membrane in the surface was visible, and the fibers were tightly in contact with the PS- $b$-P2VP matrix. However, as shown in Fig. 4c, cracking and separation occurred at the interface of the as-prepared $\mathrm{PVA} / \mathrm{SiO}_{2}$ fibers and coating layer after swelling in ethanol at $70{ }^{\circ} \mathrm{C}$. This phenomenon may be attributed to the absence of the hydrogen bonding between the -OH group on PVA and the pyridine ring in the PS$b$-P2VP matrix for the crosslinking of the silica precursor and PVA. The very smooth surfaces of the electrospun $\mathrm{PVA} / \mathrm{SiO}_{2}$ fibers also result in the weak physical interaction between the fibers and PS- $b$-P2VP matrix. In this study, the $\mathrm{PVA} / \mathrm{SiO}_{2}$ fibers were modified with a PDA layer to solve this problem and improve the interfacial adhesion.

PDA surface modification was proved to be effective and efficient for improving the interfacial adhesion of fiber-matrix composites in recent years. ${ }^{35-37}$ As illustrated in Fig. $4 \mathrm{~d}$, the interfacial nature between the PDA-coated electrospun $\mathrm{PVA} / \mathrm{SiO}_{2}$ fibers and PS- $b$-P2VP matrix was remarkably improved by PDA layer; thus, the PS- $b$-P2VP matrix could maintain contact with PDA-coated fibers even after swelling in hot ethanol of $70{ }^{\circ} \mathrm{C}$. This result could be ascribed to the hydrogen bonding interaction between pyridine groups in PS- $b$-P2VP and benzene hydroxyl groups or amine groups in PDA layer. Moreover, the $\mathrm{PVA} / \mathrm{SiO}_{2}$ fibers are rougher after modified with PDA, which also affected the interfacial adhesion between the fibers and the BCP matrix.

The nanopores in PS- $b$-P2VP were formed by a confined swelling induced pore generation mechanism. ${ }^{7,38}$ By this 
mechanism, the P2VP chains are swollen and confined in the continuous phase of the glassy PS component in hot ethanol while a slight and local plastic deformation of the PS matrix is induced. Subsequently, the ethanol is air-dried at room temperature to allow the expanded P2VP domains to shrink and the PS domains to freeze with unrecoverable deformation to produce the pores. The SEM images of the obtained nanoporous membranes swollen in hot ethanol for different times show in Fig. 5. Before swelling, no nanopores were observed (Fig. S1b †). After swelling for $10 \mathrm{~min}$, small cylindrical nanopores with disordered morphology formed. After swelling for $30 \mathrm{~min}$, a morphology intermediate between the disordered cylindrical structure and bicontinuous structure emerged. After 1 hour, the bicontinuous morphology completely developed with uniform nanopores with a diameter of $\sim 50 \mathrm{~nm}$. The nanopores slightly coarsened after swelling for a longer time.

The swelling degree of the P2VP chains and the mobility of the PS chains in ethanol depend on temperature and determine the final pore sizes to a certain extent. The influence of swelling temperature on the morphology of the final porous membrane is clearly demonstrated in Fig. 6. At a low temperature, i.e., $20^{\circ} \mathrm{C}$, the swelling degree of the P2VP minor blocks in the PS- $b$ P2VP micelles and the mobility of the glassy nonswollen PS were hardly enhanced, and almost no pores emerged in the membrane. As the temperature increased, the swelling degree of P2VP increased. Small and nonuniform nanopores appeared in the membrane surface at $30^{\circ} \mathrm{C}$ and $40^{\circ} \mathrm{C}$ (Fig. $6 \mathrm{~b}$ and c). The pores enlarged and deepened at $50{ }^{\circ} \mathrm{C}$ but remained randomly distributed. At $60{ }^{\circ} \mathrm{C}$, a bicontinuous nanostructure with extremely small pore diameter began to form. Fig. $6 \mathrm{f}$ suggests that $70{ }^{\circ} \mathrm{C}$ is an appropriate swelling temperature for PS- $b$-P2VP to form uniform and continuous nanopores.
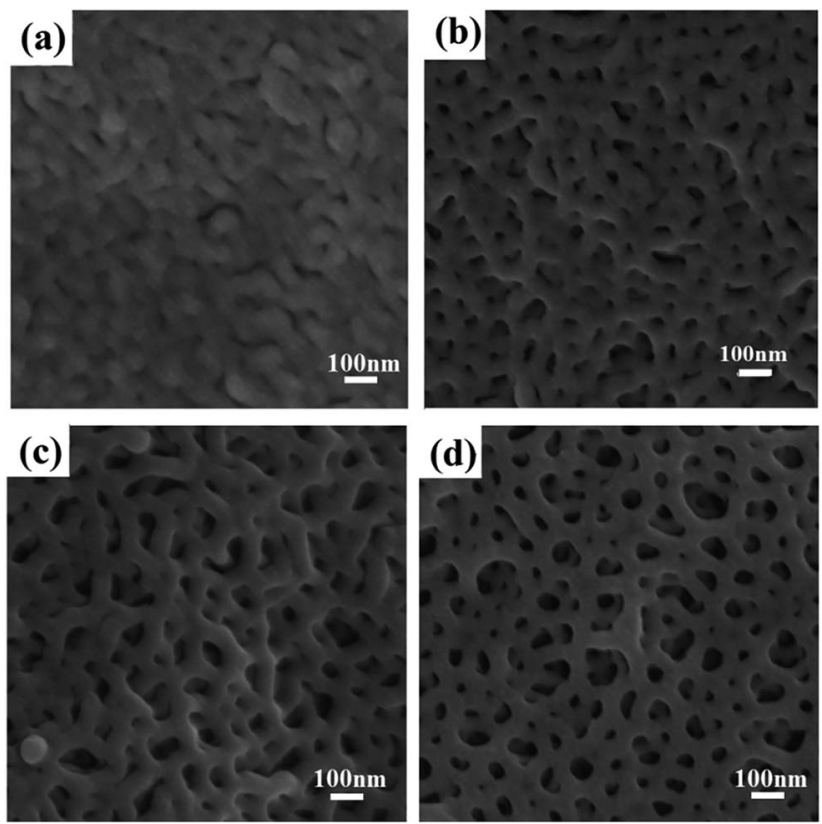

Fig. 5 SEM images of PS- $b-P 2 V P$ membranes swollen with $70{ }^{\circ} \mathrm{C}$ ethanol for different time (a) $5 \mathrm{~min}$; (b) $10 \mathrm{~min}$; (c) $30 \mathrm{~min}$; (d) 1 hour.
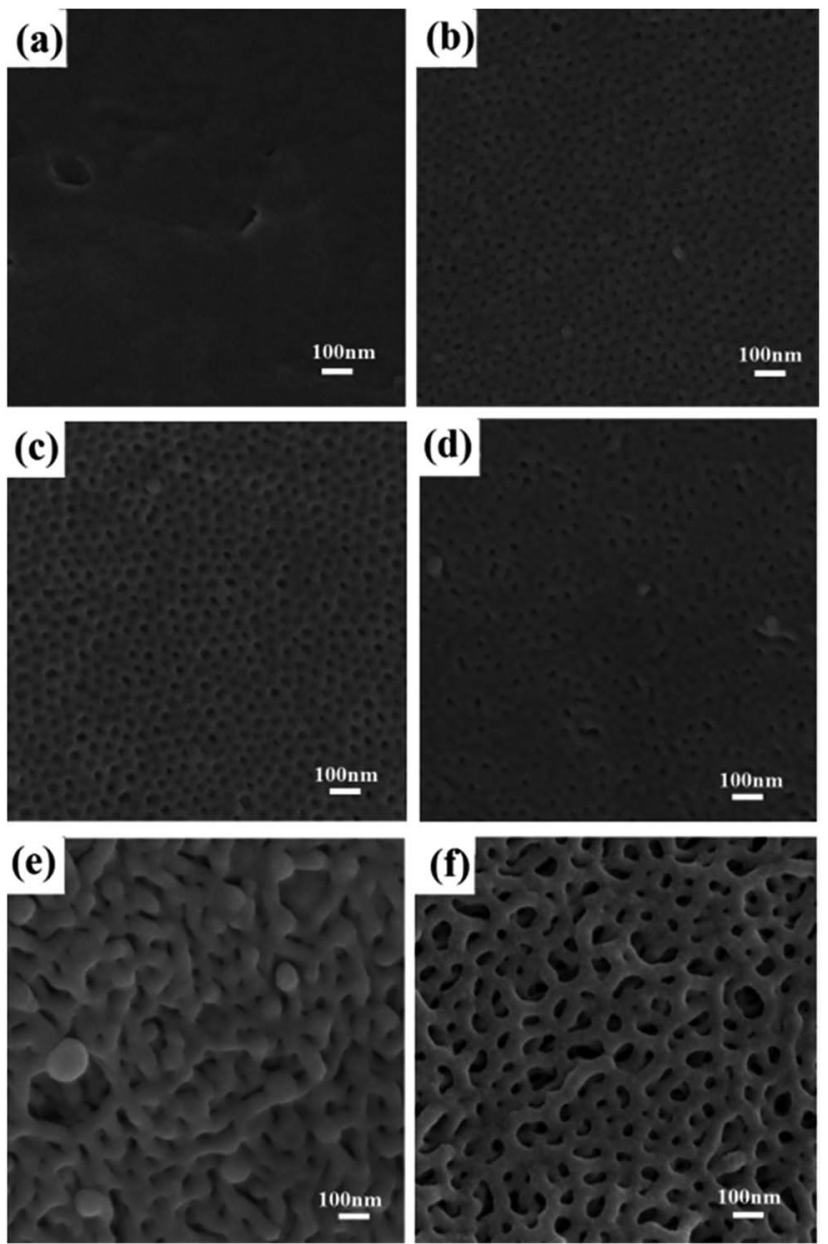

Fig. 6 SEM images of PS- $b-P 2$ VP membranes swollen with ethanol at different temperature (a) $20^{\circ} \mathrm{C}$; (b) $30{ }^{\circ} \mathrm{C}$; (c) $40{ }^{\circ} \mathrm{C}$; (d) $50{ }^{\circ} \mathrm{C}$; (e) $60^{\circ} \mathrm{C}$; (f) $70{ }^{\circ} \mathrm{C}$

In the first series of experiments, the composite membranes prepared were drop-coated with $2 \mathrm{wt} \%$ PS- $b$-P2VP. We increased the concentration of PS- $b$-P2VP to $3 \mathrm{wt} \%$ with the same casting solution volume, a membrane with all the fibers on the surface completely covered by the coating matrix was obtained, with the top surface being very smooth. The magnified top view of the composite membrane is shown in Fig. 7a. Twisted and interconnected cylinders were distributed over the entire surface of the composite membrane, whose nanopores were below $100 \mathrm{~nm}$ in size. A cross-sectional view in Fig. $7 \mathrm{~b}$ shows that the thickness of the composite membrane is $17 \pm 2 \mu \mathrm{m}$. When the concentration of PS- $b$-P2VP casting solution decreased to $1 \mathrm{wt} \%$, the macropores of the electrospun fibrous membrane could not be covered by the BCP matrix completely. After producing nanopores in the BCP filler, a hierarchical pore structure of macropores and nanopores formed (Fig. 7c and d).

\section{Preparation of asymmetric composite membrane}

Although the free-standing symmetric BCP-electrospun fiber composite membrane was obtained, its thickness reached approximately $20 \mu \mathrm{m}$. It is well known that flux performance is 

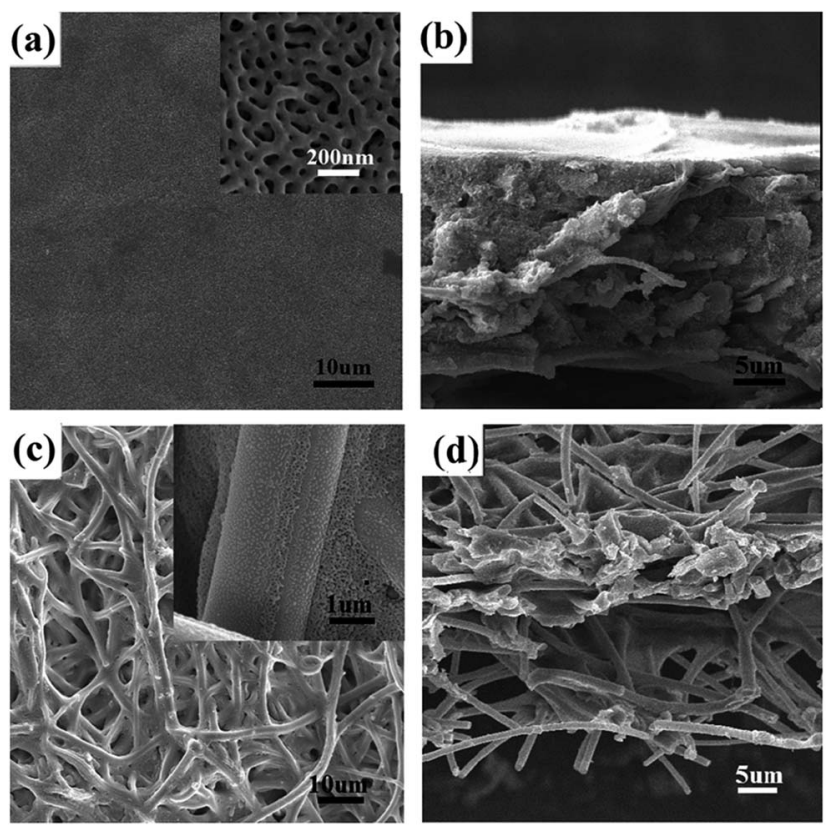

Fig. 7 SEM images of (a) the top view and (b) cross-sectional view of PS- $b$-P2VP/electrospun fibers composite membranes drop-coated with 3 wt\% PS- $b$-P2VP; SEM images of (c) the top view and (d) crosssectional view of PS- $b$-P2VP/electrospun fibers composite membranes drop-coated with 1 wt\% PS- $b$-P2VP.

inversely proportional to thickness and costs are directly related to the amount of material used. Therefore, asymmetric membranes containing thin, selective BCP layers on macroporous supports are desirable. Kim et al. used commercially available micro-filtration membranes with a broad pore size distribution as mechanical support and a BCP coating film as a selective layer to obtain a asymmetric membrane. ${ }^{39,40}$ However, a sacrificial silicon oxide layer was required in the method, which was time consuming and impractical for largescale preparation. Hillmyer et al. simplified the preparation by casting PS-PLA onto poly(ether sulfone) support directly without using a sacrificial thin film, ${ }^{17}$ but the water flow experiments demonstrated that flux was reduced significantly because of the low void fraction of PES and the perpendicular-parallel cylinder orientation deep inside the selective layer.

In the current study, we used a PDA-coated electrospun PVA/ $\mathrm{SiO}_{2}$ fibrous membrane as the macroporous support and a bicontinuous nanoporous membrane self-assembled with PS$b$-P2VP as a selective layer to prepare an asymmetric membrane. The PDA-modified $\mathrm{PVA} / \mathrm{SiO}_{2}$ fibers were immersed in water before PS- $b$-P2VP/THF solution drop-casting. When the solution was cast onto the surface of the water-wetted electrospun fibrous membrane, the casting solution permeated the water because of the intermiscibility between THF and water. However, the strong volatility of THF prevented the solution from permeating deeply. The SEM images of the top and cross sectional views of the asymmetric composite membrane drop-coated with 2 wt $\%$ PS- $b$-P2VP/THF solution are shown in Fig. 8. The macropores in the top surface of the electrospun membrane were uniformly covered by a layer of $\mathrm{BCP}$ nanoporous membrane, which was swollen in ethanol at $70{ }^{\circ} \mathrm{C}$ for 6 hours (Fig. $8 \mathrm{a}$ and c). Fig. 8b and d show that the thickness of the membrane was approximately $5 \mu \mathrm{m}$, which was significantly reduced compared with that of the symmetric composite membrane. The fibers in the surface layer were encased by the BCP matrix; as a result, the adhesion between the electrospun fibers and separation layer increased. The thickness of the BCP layer was adjusted by changing the concentration of BCP solution. As demonstrated in Fig. S2a-c, $\dagger$ the thickness of the separation layer increased with increasing concentration and was 7,4 , and $2 \mu \mathrm{m}$ respectively achieved with $3 \mathrm{wt} \%, 2 \mathrm{wt} \%$, and $1 \mathrm{wt} \% \mathrm{BCP} / \mathrm{THF}$ solution. However, the BCP layer with the thickness of $2 \mu \mathrm{m}$ was torn by tensile force upon swelling in hot ethanol due to its thinness (Fig. S2d $\dagger$ ). A thickness of $4 \mu \mathrm{m}$ was sufficient to maintain the integrity of the separation layer and increased to $\sim 5 \mu \mathrm{m}$ after swelling in hot ethanol (Fig. 8).

\section{Ultrafiltration performance evaluation}

The $17 \pm 2 \mu \mathrm{m}$-thick symmetric BCP-electrospun fiber composite membrane with a specific area of $12.08 \mathrm{~m}^{2} \mathrm{~g}^{-1}$ and an average pore diameter of $38 \mathrm{~nm}$ (Fig. 9a) was used for the evaluation of ultrafiltration performance. The result was compared with that of the as-prepared electrospun $\mathrm{PVA} / \mathrm{SiO}_{2}$ fibrous membrane with the same thickness. Fig. 9b and c show the SEM images of the top view of the composite nanoporous membrane and as-prepared electrospun fibers mat after the filtration of the Au NP dispersion. The composite membrane surface was covered with a layer of Au NPs. By contrast, the Au NPs were hardly rejected by the asprepared electrospun fibrous membrane because of the large pore size. Only a small amount of Au NPs were absorbed on the surfaces of the fibers by the chelation effect due to the $-\mathrm{OH}$
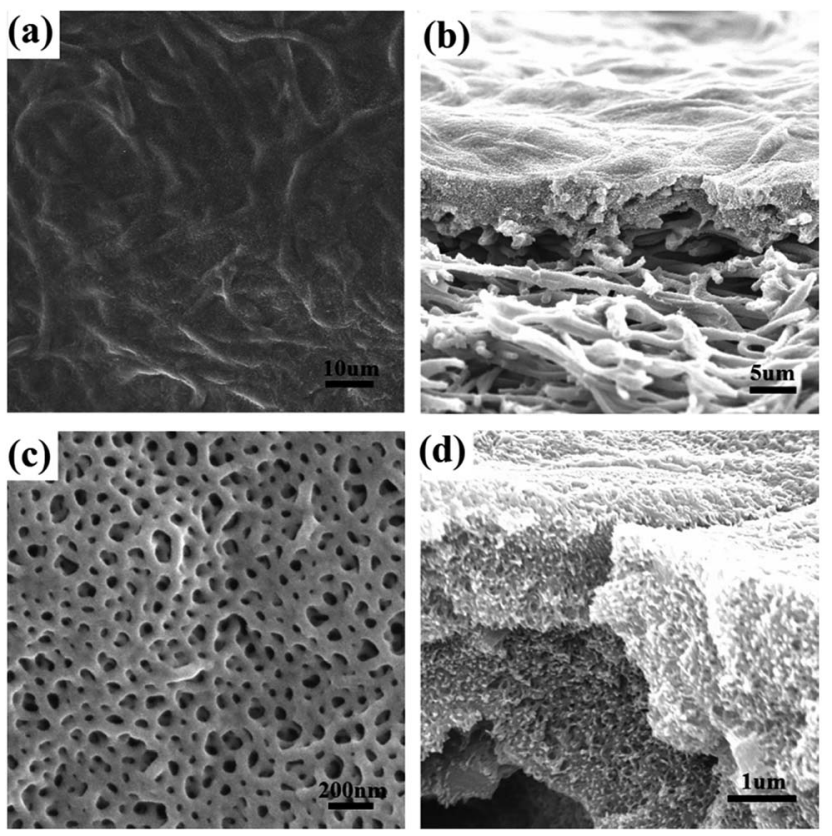

Fig. 8 SEM images of ( $a$ and $c$ ) the top view and ( $b$ and $d$ ) crosssectional view of asymmetric membrane swelling with ethanol at $70^{\circ} \mathrm{C}$ for 6 hours. 

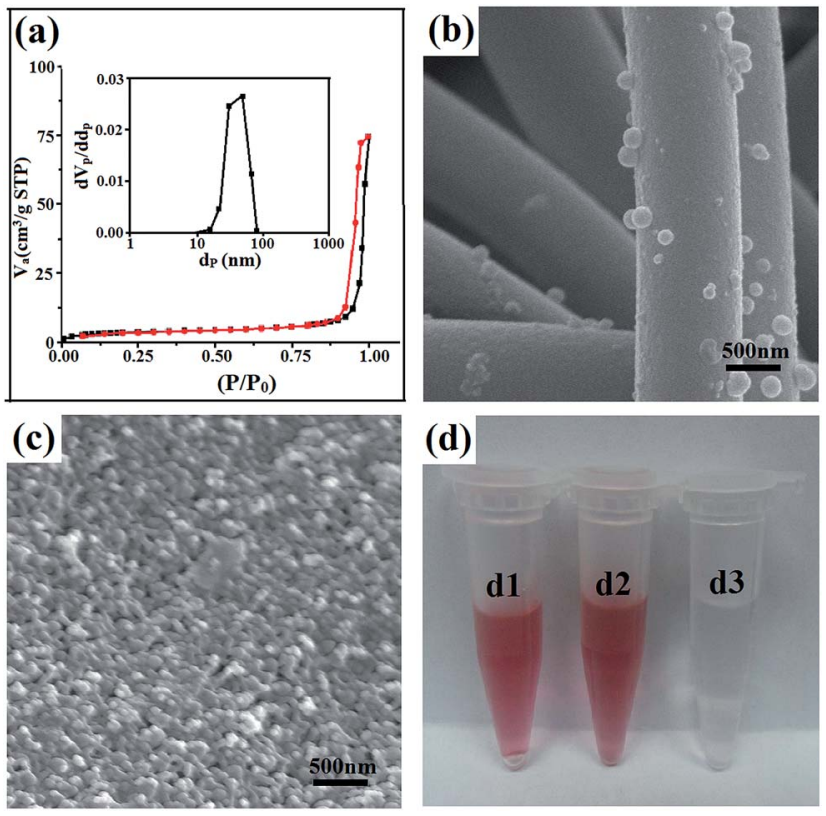

Fig. 9 (a) Nitrogen adsorption isotherm of the PDA-coated $\mathrm{PVA} / \mathrm{SiO}_{2}$ and PS- $b$-P2VP composite membrane swollen in $70{ }^{\circ} \mathrm{C}$ for 6 hours, the inset shows the pore size distribution. SEM of (b) the as-prepared electrospun fibers membrane and (c) the composite membrane after filtration of golden nanoparticles; (d) the digital photograph of the golden nanoparticle suspension (d1) before filtration, (d2) after filtration by the as-prepared electrospun fibers membrane, and (d3) after filtration by the composite membrane.

groups on the electrospun fibers. Fig. 9d shows the digital photographs of the Au NP dispersion before and after filtration. The color of the red Au dispersion nearly did not change after filtration with the as-prepared electrospun fibrous membrane, but the color disappeared after filtration with the nanoporous composite membrane. This result is consistent with the rejection phenomenon shown in the SEM images.

\section{Conclusion}

Symmetric and asymmetric membranes each composed of an

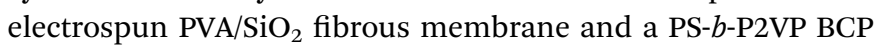
matrix were fabricated by combining electrospinning and $\mathrm{BCP}$ phase separation. The interfacial interaction between the $\mathrm{PVA} / \mathrm{SiO}_{2}$ electrospun fibers and PS- $b$-P2VP matrix was strengthened by the modification of $\mathrm{PVA} / \mathrm{SiO}_{2}$ fibers with PDA coating. The results suggest that the PDA-coated electrospun fiber mat can be tightly covered by the PS- $b$-P2VP precursor when the concentration of PS- $b$-P2VP is $3 \mathrm{wt} \%$. Furthermore, the nanopores of the composite membranes can be produced by the selective swelling of P2VP cylinders surrounded by PS matrix in the membranes. The influences of the swelling temperature and swelling time on the pore size and pore structure were also comprehensively discussed. The results indicate that the pore size and pore structure are tunable by adjusting the swelling conditions. For the asymmetric membrane, the thickness of the separation layer is tunable by varying the PS- $b$-P2VP solution concentration. A $5 \mu \mathrm{m}$-thick asymmetric nanoporous membrane was successfully obtained by our strategy. The result of the ultrafiltration performance evaluation indicates that the composite membrane can be used for the efficient separation of NPs, which informs that this hierarchical porous composite membrane is a promising candidate for industrial and environmental applications.

\section{Conflicts of interest}

There are no conflicts to declare.

\section{Acknowledgements}

We sincerely thank the Key Laboratory of Subsurface Hydrology and Ecological Effects in Arid Region, Ministry of Education. This work was funded by Natural Science Basic Research Plan in Shaanxi Province of China (2017JQ5008; 2017JQ2042) and the Fundamental Research Funds for the Central Universities of China (310829161017; 310829173602; 310829161006; 310829172002), One Hundred Talent Plan of Shaanxi Province and the Innovation Training Program for Undergraduate Students of Chang'an University (201610710079).

\section{Notes and references}

1 A. Greiner and J. H. Wendorff, Angew. Chem., 2007, 46, 56705703.

2 R. Sahay, P. S. Kumar, R. Sridhar, J. Sundaramurthy, J. Venugopal, S. G. Mhaisalkar and S. Ramakrishna, J. Mater. Chem., 2012, 22, 12953-12971.

3 S. Mohammadzadehmoghadam, Y. Dong and I. Jeffery Davies, J. Polym. Sci., Part B: Polym. Phys., 2015, 53, 11711212.

4 S. S. Homaeigohar, K. Buhr and K. Ebert, J. Membr. Sci., 2010, 365, 68-77.

5 P. van Rijn, M. Tutus, C. Kathrein, L. Zhu, M. Wessling, U. Schwaneberg and A. Boeker, Chem. Soc. Rev., 2013, 42, 6578-6592.

6 H. Ahn, S. Park, S.-W. Kim, P. J. Yoo, D. Y. Ryu and T. P. Russell, ACS Nano, 2014, 8, 11745-11752.

7 Y. Wang, Acc. Chem. Res., 2016, 49, 1401-1408.

8 J. I. Clodt, V. Filiz, S. Rangou, K. Buhr, C. Abetz, D. Höche, J. Hahn, A. Jung and V. Abetz, Adv. Funct. Mater., 2013, 23, 731-738.

9 Z. Yi, P.-B. Zhang, C.-J. Liu and L.-P. Zhu, Macromolecules, 2016, 49, 3343-3351.

10 H. Uehara, M. Kakiage, M. Sekiya, D. Sakuma, T. Yamonobe, N. Takano, A. Barraud, E. Meurville and P. Ryser, ACS Nano, 2009, 3, 924-932.

11 M. Karunakaran, R. Shevate and K.-V. Peinemann, RSC Adv., 2016, 6, 29064-29071.

12 S. P. Nunes, Macromolecules, 2016, 49, 2905-2916.

13 F. Schacher, M. Ulbricht and A. H. Müller, Adv. Funct. Mater., 2009, 19, 1040-1045. 
14 Y. Xie, N. Moreno, V. M. Calo, H. Cheng, P.-Y. Hong, R. Sougrat, A. R. Behzad, R. Tayouo and S. P. Nunes, Polym. Chem., 2016, 7, 3076-3089.

15 M. Seo, D. Moll, C. Silvis, A. Roy, S. Querelle and M. A. Hillmyer, Ind. Eng. Chem. Res., 2014, 53, 18575-18579.

16 S. Schoettner, H.-J. Schaffrath and M. Gallei, Macromolecules, 2016, 49, 7286-7295.

17 W. A. Phillip, B. O'Neill, M. Rodwogin, M. A. Hillmyer and E. L. Cussler, ACS Appl. Mater. Interfaces, 2010, 2, 847-853.

18 X. Yao, L. Guo, X. Chen, J. Huang, M. Steinhart and Y. Wang, ACS Appl. Mater. Interfaces, 2015, 7, 6974-6981.

19 X. Li, C.-A. Fustin, N. Lefèvre, J.-F. Gohy, S. De Feyter, J. De Baerdemaeker, W. Egger and I. F. Vankelecom, J. Mater. Chem., 2010, 20, 4333-4339.

20 W. Sun, Z. Wang, X. Yao, L. Guo, X. Chen and Y. Wang, J. Membr. Sci., 2014, 466, 229-237.

21 H. Zhou, Y. Su, X. Chen, J. Luo, S. Tan and Y. Wan, J. Membr. Sci., 2016, 520, 779-789.

22 H. Li, L. Tuo, K. Yang, H.-K. Jeong, Y. Dai, G. He and W. Zhao, J. Membr. Sci., 2016, 511, 130-142.

23 L. Jin, M. Zhang, H. Li, M. Li, L. Shang, L. Xiao and Y. Ao, RSC Adv., 2016, 6, 80485-80492.

24 A. Abdolmaleki, S. Mallakpour and S. Borandeh, Polym. Compos., 2016, 37, 1924-1935.

25 L. Wang, Y. Shi, R. Sa, N. Ning, W. Wang, M. Tian and L. Zhang, Ind. Eng. Chem. Res., 2016, 55, 12547-12556.

26 H. Lee, S. M. Dellatore, W. M. Miller and P. B. Messersmith, Science, 2007, 318, 426-430.
27 M. Hu and B. Mi, Environ. Sci. Technol., 2013, 47, 37153723.

28 J. Zhao, C. Fang, Y. Zhu, G. He, F. Pan, Z. Jiang, P. Zhang, X. Cao and B. Wang, J. Mater. Chem. A, 2015, 3, 1998019988.

29 Y. Li, Y. Su, J. Li, X. Zhao, R. Zhang, X. Fan, J. Zhu, Y. Ma, Y. Liu and Z. Jiang, J. Membr. Sci., 2015, 476, 10-19.

30 H. Lee, J. Rho and P. B. Messersmith, Adv. Mater., 2009, 21, 431-434.

31 C. Shao, H. Y. Kim, J. Gong, B. Ding, D. R. Lee and S. J. Park, Mater. Lett., 2003, 57, 1579-1584.

32 M. Krissanasaeranee, T. Vongsetskul, R. Rangkupan, P. Supaphol and S. Wongkasemjit, J. Am. Ceram. Soc., 2008, 91, 2830-2835.

33 T. Pirzada, S. A. Arvidson, C. D. Saquing, S. S. Shah and S. A. Khan, Langmuir, 2012, 28, 5834-5844.

34 H. Yang, Y. Lan, W. Zhu, W. Li, D. Xu, J. Cui, D. Shen and G. Li, J. Mater. Chem., 2012, 22, 16994-17001.

35 W. Lee, J. U. Lee and J. H. Byun, Compos. Sci. Tech., 2015, 110, 53-61.

36 M. Yi, H. Sun, H. Zhang, X. Deng, Q. Cai and X. Yang, Mater. Sci. Eng., C, 2016, 58, 742-749.

37 Y. Li, Q. Chen, M. Yi, X. Zhou, X. Wang, Q. Cai and X. Yang, Appl. Surf. Sci., 2013, 274, 248-254.

38 Y. Wang and F. Li, Adv. Mater., 2011, 23, 2134-2148.

39 S. Y. Yang, I. Ryu, H. Y. Kim, J. K. Kim, S. K. Jang and T. P. Russell, Adv. Mater., 2006, 18, 709-712.

40 S. Y. Yang, J. Park, J. Yoon, M. Ree, S. K. Jang and J. K. Kim, Adv. Funct. Mater., 2008, 18, 1371-1377. 